\title{
Contracepção e controle da natalidade: enfoque bioético
}

\author{
Contraception and birth control: bioethical focus
}

\author{
Marcos de Almeida ${ }^{1}$
}

\begin{abstract}
"Sinto-me nascido a cada momento Para a eterna novidade do Mundo..." Fernando Pessoa, Poemas completos de Alberto Caieiro, 1935
\end{abstract}

Almeida M. Contracepção e controle da natalildade: enfoque bioético. Saúde, Ética \& Justiça. 2010;15(1):35-9.

Resumo: No presente artigo, desenvolve-se uma reflexão a respeito da contracepção. O autor demonstra a necessidade do controle de natalidade e rebate argumentos contrários aos métodos contraceptivos, como os que afirmam tratar-se de algo condenável por ser artificial ou antinatural.

Descritores: Controle de natalidade; Contracepção; Bioética.

INTRODUÇÃO

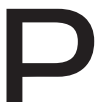
reocupação com 0 crescimento populacional é somente uma dentre as muitas questões assinaladas nas agendas dos governantes mundiais e, seria justo dizer, que, quando comparada com problemas imediatos, como obtenção de energia, alimentação, educação, saúde e reformas constitucionais, fica bem abaixo destas na hierarquia das prioridades políticas.

Não obstante, como Canuto $^{1}$ aprendeu na sua confrontação com a maré, alguns processos possuem uma força inexorável e nunca desaparecerão por si sós, nem cessarão por mero requerimento. $O$ crescimento populacional é um desses processos. Nos últimos anos, uma discussão cerrada sobre que ações seriam adequadas para fazer frente ao fluxo da reprodução humana, deu entrada na arena das questões internacionais, e agosto de 1974 ficará marcado como o momento histórico da realização da $1^{\underline{a}}$ Conferência Internacional sobre o assunto, realizada em Bucareste.

Embora no passado tenham ocorrido extensos debates sobre as vantagens e desvantagens do crescimento populacional, dificilmente haveria nos dias correntes algum político responsável que defendesse a idéia de que o crescimento pudesse, logicamente, continuar para sempre. Todos, literalmente todos, concordam que, no longo termo, a necessidade de "crescimento zero" será vista mais como verdade insofismável do que como mero slogan, pois a alternativa do incessante crescimento populacional em um mundo fisicamente finito é um patente e patético absurdo.

\footnotetext{
1 Médico livre-docente em Bioética pela USP, professor titular da disciplina de medicina legal e bioética da Universidade Federal de São Paulo, UNIFESP - EPM.

Endereço PARA CORRESPONdÊnCIA: Marcos de Almeida. EPM/UNIFESP. Rua Botucatu, 720 - Vila Clementino, São Paulo, SP - CEP: 01532-000
} 
Almeida M. Contracepção e controle da natalildade: enfoque bioético.

Duas correntes têm se debatido no centro do cenário: os que acham que os esforços devem dirigir-se especificamente para a redução do crescimento direto e os que julgam ser bastante a instituição de programas que levem ao desenvolvimento econômico e social.

Advogados de ambas as partes extremadas tomam a palavra e levam o assunto para uma polarização política e ideológica de grandes proporções. Por um lado, a chamada "bomba populacional" é responsabilizada por todos os males do mundo, incluindo a fome, a pobreza, a poluição, o crime e até a doença mental. A partir dessa perspectiva, tais problemas poderiam ser resolvidos via programas populacionais voluntários ou coercitivos; bastaria vontade política e recursos financeiros. Por outro lado, os advogados da postura oposta, repetidamente levantam-se para negar a saliência do atual crescimento populacional como um problema e enfatizam a suficiência de um programa desenvolvimentista para resolver as questões.

É uma estranha hemiplegia mental que assola os entusiastas de ambos os lados, já que nada há que impeça a implementação vigorosa dos dois programas, simultaneamente.

\section{O CONTROLE DA NATALIDADE}

É freqüentemente afirmado, embora de modo algo incorreto, que o chamado movimento pelo controle da natalidade teve o seu começo nas teorias populacionais do Reverendo Thomas R. Malthus, um clérigo anglicano que publicou, em 1798, um ensaio intitulado "On Principles of Population as it Affects the Future Improvement of Society"4.

Sua tese era a de que o grau de crescimento populacional tende a aumentar mais rapidamente que os meios de subsistência e necessita, portanto, ser controlado, quer por métodos positivos, embora não propositalmente impostos (fome, doença e guerra), quer por métodos preventivos (redução, por alguns meios, do número de nascimentos). Deve ser aqui enfatizado que ele não recomendou o uso de dispositivos contraceptivos. Apenas insistiu na afirmação de que a população aumenta em proporção geométrica, enquanto que a fertilidade do solo e a produção de alimentos aumentam somente em proporção aritmética. As recomendações de Malthus, como controle preventivo, resumiam-se a casamento tardio, abstinência dentro do casamento, diminuição do número de casamentos e até, ausência de casamento. Ele não deu sua aprovação aos dispositivos contraceptivos, embora muitos deles já fossem conhecidos na ocasião.

\section{O PROBLEMA}

$\mathrm{Na}$ abordagem dos aspectos éticos e legais da anticoncepção, faz-se necessário destacar dois importantes fatos: o primeiro é o de que o avanço da ciência e da tecnologia médica, nas últimas décadas, adicionou urgência aos velhos problemas, os ressalientou e, sobretudo, criou inúmeros outros problemas. Por outro lado, o descompasso que inevitavelmente caracteriza as novas conquistas, passando pela incorporação de novos costumes na sociedade, até a elaboração de novas normas e códigos, põe em evidência a inadequação das codificações vigentes.

Logo de início é indispensável que se estabeleça, muito claramente, que o controle da natalidade em si próprio não está sob questão. O problema central repousa na eticidade dos meios de controle da reprodução humana.

Existem pelo menos cinco meios de controle:

1. Pela abstinência ou continência;

2. Pela restrição da atividade sexual, ao dito período infértil do ciclo feminino;

3. Pelo uso de vários meios mecânicos e químicos, métodos que podem ser chamados de anticoncepcionais;

4. Pela cirurgia (laqueadura ou vasectomia);

5. Pelo aborto.

Os dois primeiros processos não costumam ser questionados no terreno ético. Todavia, quaisquer que sejam teoricamente suas virtudes, a continência não está, precisamente, entre as vocações dos casais. A própria razão do casamento é, de certo modo, uma contradição do celibato. Além disso, tanto o senso comum como a psiquiatria, nos fornecem algumas fortes razões para não considerar a abstinência como 
um método ideal e seguramente não universal de controle.

De outro lado, o último modo citado, ou seja, o aborto está igualmente fora das cogitações do presente estudo, por não ser um meio preventivo da concepção.

A qualidade moral de qualquer escolha que se faça é invariavelmente determinada por duas coisas: a) pela intenção envolvida, ou melhor, o fim procurado; b) pelos meios utilizados.

O fim almejado em qualquer das práticas é o mesmo, ou seja, a prevenção da concepção. Portanto, se qualquer das práticas for proibida, ela terá de sê-lo por que o meio é inerentemente ou intrinsecamente errado. É precisamente neste terreno que alguns moralistas, sobretudo os católicos, condenam os contraceptivos. De que forma então, eles demonstram esta suposta imoralidade? Este é o problema decisivo.

Dois dos termos freqüentemente utilizados pelos opositores da anticoncepção são: artificial e antinatural. $\mathrm{O}$ uso de tais termos evidentemente não tem qualquer peso de argumentação. Servem apenas ao interesse de alguns slogans populares, tais como "a maldição moral do controle artificial da natalidade", em prejuízo da clareza acerca de seu próprio significado ${ }^{4}$.

$\mathrm{Na}$ realidade, não se pode condenar os contraceptivos simplesmente porque são meios artificiais. Eles são artificiais na mesma medida em que a própria medicina o é!

Óculos, muletas e próteses são também objetos não fornecidos pela natureza. Não obstante esses moralistas consideram que estes objetos inaturais, são meios morais para legitimar propósitos, por que auxiliam os fins tencionados pela natureza, isto é, ver, andar e comer.

A real objeção procede de que os anti-conceptivos, além de antinaturais, subvertem ou evitam um fim tencionado pela natureza. Os argumentos alegam três pontos de muita debilidade e até ingenuidade:

1) é imoral, através de meios positivos, impedir um fim tencionado pela natureza; 2) desde que os contraceptivos são meios positivos para impedir um fim tencionado pela natureza, eles são logicamente imorais; 3) já que o ritmo não impede, por meios positivos, um fim tencionado pela natureza, ele é moralmente lícito.
Naturalmente que se pode argumentar que a natureza, no geral, deseja que o homem se reproduza, pois o equipou com órgãos reprodutores e impulsos biológicos e, portanto, que a continência ou mesmo a relação sexual restrita ao período infértil, são interferências com o propósito da natureza, tanto quanto o celibato, e que por isso não existiria método correto ou natural de controle do nascimento.

Mas aqui voltamos ao ponto inicial. Toda a realidade desse silogismo simplista repousa na assertiva de que, de fato, a natureza tem "intenções", o que, na verdade, é um patética falácia que se invalida pelos próprios argumentos. Um exame mais atento dos fatos não ajuda essa tentativa de determinar o que a natureza "tenciona" observando o que de fato acontece. Ao contrário do que os teólogos clássicos afirmam, os fatos parecem solapar a alegação de que o sexo natural deseja a reprodução. Parece que pelo princípio da preponderância estatística é precisamente o inverso que é verdadeiro. Se não, vejamos. Nos 28 dias do ciclo menstrual, somente 6 são férteis e 22 inférteis. Uma mulher pode conceber, regra geral, dos 13 aos 45 anos, ou 32 anos de 13 ciclos, num total de 2.496 dias férteis contra 9.152 dias inférteis! A sexualidade normal continua até por volta dos 66 anos, adicionando assim, 7.665 dias inférteis ao período sexualmente ativo, totalizando 19.313 dias com somente 2.496 deles férteis (1 em cada 8 aproximadamente). Se aceitarmos que a natureza implantou em nós o desejo sexual e "tenciona" a relação e, mais ainda, que as "intenções da natureza" são mais evidentes na regra do que na exceção, pode-se concluir que o propósito primário da natureza quanto ao sexo é, muito mais, a satisfação do desejo do que gerar filhos. Como método para demonstrar que a procriação é o fim primário da sexualidade, esta espécie de versão estatístico-materialista da lei natural, destroi-se a si própria.

Com a tecnologia médica da contracepção, a paternidade e o nascimento tornaram-se questões de responsabilidade moral e, portanto, de escolha inteligente e deliberada. Somos capazes de controlar nossa fertilidade. Não temos mais que escolher, inevitavelmente, entre reprodução e continência. O sexo já não é mais uma submissão fatalista às "determinações" 
Almeida M. Contracepção e controle da natalildade: enfoque bioético.

biológicas. Nem a única alternativa é a negação do amor sexual, quer completamente quer de acordo com cálculos de duvidoso ritmo matemático. Quando tais cálculos participam da relação, a espontaneidade desaparece.

O ritmo é uma negação de liberdade; oferece somente uma alternativa de eventual necessidade e não um método rotineiro de verdadeiro controle.

Nossa discussão pode agora ser resumida com algumas observações separadas. Salta aos olhos que a concepção católica de Lei Natural é altamente questionável. Nenhum cientista (e, menos que todos, um médico) pode aceitar o ponto de vista de que a natureza "tenciona" o que quase sempre ou freqüentemente ocorre. $O$ determinismo causa e efeito do último século não é mais endossado pelos filósofos da ciência ${ }^{5}$. Mesmo que endossassem, existe uma razão teologicamente séria, para contestar a idéia de que Deus, como inteligência criativa, "tenciona" que tudo na natureza deva ser aceito e considerado como bom ${ }^{6}$.

Podemos com segurança reafirmar nosso princípio anterior de que a estatura moral do homem, seu status verdadeiramente humano é medido pelo seu conhecimento das próprias circunstâncias (incluindo a natureza física) e por sua habilidade para controlar essas circunstâncias no sentido de fins escolhidos mais do que determinados fatalisticamente.

Por todos estes motivos temos de concordar com George Bernard Shaw, que disse que "a diferença entre a atividade racional, voluntária e controlada, e qualquer tipo de atividade irracional, involuntária e incontrolada é a exata diferença entre uma ameba e um homem. E se acreditamos de fato que a criatura mais evoluída é a melhor, deveríamos agir sempre de acordo com isso"1. O Comitê Britânico de Controle da Natalidade, argumenta que "a própria civilização tem sido a história do controle do homem sobre a natureza através dos mais variados meios". ${ }^{11}$ Foi igualmente nesse espírito que Sigmund Freud escreveu: "seria um dos grandes triunfos da humanidade se fosse possível elevar o ato irresponsável da procriação ao nível de um ato voluntário e intencional e liberá-lo de seus inter-relacionamentos com uma indispensável satisfação da natureza"”.

O cuidado médico atual em natalidade não é mais mero "serviço de cegonha". Abrange um amplo espectro de cuidados pré e pós-natais. Os contracepcionais, neste campo da medicina, dão aos pacientes os meios pelos quais eles podem ser pessoas e não meramente corpos.

Presumivelmente Deus deu ao homem tanto os órgãos genitais como o cérebro. E este deveria ser usado pelo menos tantas vezes quanto os primeiros. E nós acrescentaríamos que a inteligência deveria ser usada tão intensamente e não apenas tão freqüentemente, na medida em que somos seres racionais.

Quanto à cirurgia de ligadura de trompa ou de ducto deferente, suscita outros tipos de controvérsia quanto à sua moralidade e/ou legalidade. Considerada liminarmente por alguns como infringência do parágrafo segundo do artigo 129 do Código Penal Brasileiro, pode perfeitamente ter sua ilicitude contestada. Considerando que todo delito exige, quer a existência de culpa em seu sentido aquiliano (imperícia, imprudência ou negligência), quer a existência de uma intenção ou "animus" doloso (laedendi, vulnerandi ou necandi), estaria descaracterizada a ilicitude do fato, se ficasse comprovada a existência do que poderíamos chamar de "animus curandi".

Nossos juízes e cortes de justiça jamais concederiam a guarda ou adoção de uma criança a quaisquer pessoas com instabilidade emocional ou insanidade mental comprovada. Suas objeções apoiam-se em terreno moral: uma criança tem direito a um padrão mínimo de cuidados e segurança, e os pais naturais ou adotivos são obrigados, por dever imperativo de lei e de consciência a possuir a competência necessária para dispensar, a seus filhos, esses cuidados. Sob o ponto de vista dessas obrigações paternas e maternas, não se pode evitar a pergunta: Se a lei não permite, a pessoas não capacitadas, adotar uma criança, porque deveria permiti-las conceber e fazer nascer de forma indiscriminada e irresponsável?

O curioso é que a igreja católica, usando tanto a teologia da penitência, quanto a regra do duplo efeito conseguiu, de algum modo, justificar a esterilização de garotos, de sorte a fornecer vozes de soprani castrati, as famosas volci bianchi, para os coros sistinos em Roma desde Silvestre I, no século IV D.C,. até pelo menos Leão XIII, em 1884. Se a esterilização pode ser justificada em 
prol de um coro terrestre capaz de entoar música celestial, ${ }^{10}$ seguramente podemos encontrar um modo de justificá-la por outra razão moralmente ainda mais importante: o bem estar físico e a harmonia espiritual do ser humano.

Nossa postura é contrária ao naturalismo em Ética, pois isso a transformaria em algo primitivo e animistico. Não estamos sugerindo uma guerra à natureza, inclusive porque somos seres da natureza. No entanto, não somos seres exclusivamente da natureza, somos seres também da natureza. A dimensão humana vai muito além da categoria do natural e engloba a estatura do cultural e do espiritual. Nossa idiossincrasia contra a visão naturalística é apenas no sentido em que ela equipara (e minimiza) a condição humana a uma mera condição física. Simplesmente, por uma questão de lógica elementar, não podemos e não devemos nos submeter à mera fisiologia e seus padrões não racionais, pois isso seria renunciar ao nosso status verdadeiramente moral.

É impossível forjar uma sociedade de homens saudáveis, dignos e decentes sem atender tanto à natureza como à cultura. ${ }^{8} \mathrm{~A}$ estatura espiritual, e particularmente a moral, emerge a partir da cultura. Na realidade, a cultura da responsabilidade pessoal, significa precisamente que a natureza está sendo qualificada pelo espírito e o homo sp. está se tornando homo sapiens.

Almeida M. Contraception and birth control: bioethical focus. Saúde, Ética \& Justiça. 2010;15(1):35-9.

Resumo: The following article composes a discussion about the contraception issue. The author presents ideas explaining why birth control is needed and refutes arguments against contraception as those which claim that it is something wrong because it is artificial or unnatural.

KEYWORDS: Birth control; Contraception; Bioethics.

\section{REFERÊNCIAS}

1. Berril NJ. Sex and nature of things. New York: EUF Payne; 1953.

2. Breasted JH. The dawn of conscience. New York: Ed. The Ronald Press Co.; 1938.

3. Connel FJ. The intrinsic evil of condomistic relations. Am Eccles Rev. 1943;108:38-9

4. Doniger S. Sex and religion today. New York: J.E. Calcutt ed.; 1953.

5. Engelhart HT Jr. The foundations of bioethics. New York: Oxford University Press; 1986.

6. Ford N. Impact of advances in science and technology on moral theology. Compass Theology Rev.
1987;21:23-8.

7. Freud S. Collected papers. London: Oxford University Press; 1940.

8. Holmes SJ. Life and morals. New York: Alfred Knopf; 1948.

9. Huxley AJ. Ape and essence. London: P. Chalmus Mitchell ed.; 1948.

10. Migne JP. Theologiæ cursus completus. Montrouge: Ed. Nicaise; 1841

11. Rozenfeld A. The second genesis: the coming control of life. New Jersey: Prentice Hall, E. Cliffs; 1969. 